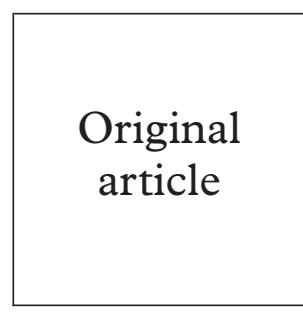

\title{
Macrophages are increased in cervical epithelium of women with cervicitis
}

\author{
Manyu Prakash, Steven Patterson, Moses S Kapembwa
}

Background: Sexually transmitted diseases (STIs) are major causes of morbidity in women. The mechanisms involved in establishment of genital mucosal infection are poorly defined.

Objective: To investigate changes in cervical epithelial (CE) CD45+ cell subpopulations in women with microscopic evidence of cervicitis $(n=9)$ and those without $(n=12)$.

Methods: CE samples were obtained using cytobrush including matched venous blood. CE and peripheral blood (PB) mononuclear cells were analysed by flow cytometry for CD3+, CD4+, CD8+, CD14+,CD19+, and HLA-DR+ expression.

Results: Women with cervicitis had increased CE macrophages compared with those without $(\mathrm{p}<0.05)$. MHC class II+ cells were predominant in all cervical samples. Considerably fewer B lymphocytes were found in cervical samples in both groups of women. No changes were observed in cervical T lymphocyte subsets. However, a relative CD8+ lymphocytosis in PB was noted in women with cervicitis.

Conclusion: The increased numbers of CE macrophages in women with cervicitis may have important implications for pathogenesis of STIs including human immunodeficiency virus infection.

(Sex Transm Inf 2001;77:366-369)

Keywords: cervicitis; macrophages; flow cytometry

\section{Introduction}

Knowledge of the type and distribution of cells in the cervical mucosa is critical to understanding the pathogenesis of sexually transmitted infections in women. ${ }^{1-3}$ Furthermore, formulating strategies to prevent such infections requires a basic understanding of the local immune response in the female genital tract and its relation to systemic immunity.

Few studies have investigated the manner in which micro-organisms are transported across the mucosa ${ }^{45}$ and the specific changes in cellular components associated with progression or elimination of such infections. ${ }^{67}$ In particular, reports on the distribution of immunocompetent cells in the female genital tract in humans have yielded conflicting results, with some workers showing more CD4+ T lymphocytes than CD8+ T lymphocytes, ${ }^{89}$ while others found $\mathrm{CD} 8+\mathrm{T}$ cells to be the major $\mathrm{T}$ lymphocyte subset. ${ }^{10} \mathrm{~A}$ dilemma that confounds interpretation of these findings in most studies concerns the variability in the methods used to collect samples, subject selection, and the different assessment techniques.

The cytobrush technique overcomes many of these problems and is an appropriate method for quantitative analysis of cervical cells. We have previously used this non-invasive cervical sampling method to quantitate leucocyte subsets within the cervical epithelium of healthy women using fluorescent activated cell sorter (FACS) analysis. ${ }^{11}$

The aims of the study were, firstly, to investigate changes in lymphocyte and mononuclear phagocyte populations in cervical epithelium of women with and without cervicitis and, secondly, to compare and contrast such changes with matched peripheral blood from the same individuals.

\section{Methods}

SUBJECTS AND MATERIALS

The study group consisted of 21 women attending the genitourinary medicine department for sexual health screening or seeking investigation of vaginal discharge. Details of the menstrual and sexual history including parity, contraception method, number of sexual partners in the preceding 3 years, and previous sexually acquired infections were obtained from all women. None of the participants was taking immunosuppressive, antiinflammatory, or antibiotic therapy at the time of study. The study received approval from the local hospital ethics committee. All women underwent a standardised speculum examination including cervical inspection for presence of mucopus, oedema, ectopy, and erythema.

The ectocervix was wiped clean with a large swab and samples of endocervical secretions obtained using the microloop technique, then smeared directly onto slides for screening of Chlamydia trachomatis using direct immunofluorescence (Syva MicroTrac, UK). In addition, cervical swabs were cultured for Neisseria gonorrhoeae and herpes simplex virus (HSV) using standard methodologies. Gram stained preparations were examined for polymorphs, epithelial cells, candida spp, and bacteria, and wet smears for Trichomonas vaginalis.

A fine cervical cytobrush (Medscand AB, Sweden) was placed within the cervical canal and samples of cervical epithelium obtained as previously described. ${ }^{11}$

A heparinised venous blood sample was obtained at the time of cervical sampling for 
Key messages

- Cytobrush sampling flow cytometry is an appropriate method to identify and quantify immune cells in the endocervical epithelial layer in normal, healthy women and women with cervicitis.

- Women with cervicitis had higher number of macrophages, not lymphocytes, in endocervical epithelium compared with those without.

- MHC class II cells were dominant CD45 mononuclear cells harvested in both groups of women supporting the concept that most endocervical epithelial cells are capable of presenting antigen to $\mathrm{T}$ lymphocytes.

- In contrast with cervical epithelia, a relative CD8 T lymphocytosis was detected in peripheral blood of women with cervicitis compared with those without, the significance of which is uncertain.
Table 1 Clinical and demographic features of women with cervicitis $(n=9)$ compared with those of women without cervicitis $(n=12)$

\begin{tabular}{lll}
\hline & $\begin{array}{l}\text { Without } \\
\text { cervicitis } \\
(n=12)\end{array}$ & $\begin{array}{l}\text { With } \\
\text { cervicitis } \\
(n=9)\end{array}$ \\
\hline Age (years) & $33(3)$ & $30(3)$ \\
$\quad$ Mean (SE) & $18-55$ & $20-49$ \\
$\quad$ Range & 4 & 5 \\
Parity & 2 & 2 \\
$\quad$ Nulliparous & 6 & 2 \\
$\quad$ Primiparous & 3 & 6 \\
$\quad$ Multiparous & & \\
Previous STI & 6 & 5 \\
Presenting complaint & & \\
$\quad$ Vaginal discharge & 2 & 5 \\
Contraception & 2 & 3 \\
$\quad$ Combined oral contraception & 0 \\
$\quad$ Condom & 2 & 1 \\
$\quad$ Intrauterine device & 6 & 8 \\
$\quad$ No contraception & & 0 \\
Ethnicity & 8 & 1 \\
$\quad$ White & 0 & 0 \\
$\quad$ Afro-Caribbean & 3 & \\
$\quad$ Msian & 1 & \\
\hline
\end{tabular}

ansis. Slood mononuclear cell (PBMC) known to influence immunological function and lymphocyte populations in peripheral blood, ${ }^{12}$ cervical and venous blood samples were collected during mid-cycle (median 13 day, range 6th and 28th day of the menstrual cycle). Matched cervical and blood samples were transported to the laboratory and processed within 2 hours of collection.

MICROSCOPIC ASSESSMENT OF INFLAMMATION IN CERVICAL EPITHELIUM

Cervicitis has previously been defined on the basis of visual presence of mucopus in endocervical exudate, ${ }^{13}$ histological examination of the cervix, ${ }^{14}$ or quantitation of leucocytes in cervical exudate. ${ }^{15}$ Only the latter method was used for assessment of cervicitis in this study.

Gram stained endocervical smears were evaluated independently by one microscopist (MK). Polymorphonuclear leucocytes (PMNL) were counted in five non-adjacent oil immersion fields $(\times 1000)$. The number of PMNLs per high power field (HPF) was recorded as either $0-40$ per HPF or greater than 40 per HPF. Women showing less than 40 PMNLs per HPF were considered normal whereas those with greater than 40 PMNLs per $\mathrm{HPF}$ comprised the cervicitis group.

IDENTIFICATION OF MONONUCLEAR CELLS FROM CERVICAL AND PERIPHERAL BLOOD SAMPLES Mononuclear cells from cervical and peripheral blood were isolated and surface stained using a panel of mononuclear antibodies to determine cellular phenotypes as previously described. ${ }^{11}$

\section{STATISTICAL ANALYSIS}

The Student's $t$ test was used to determine the significance of differences in cellular subpopulations between women with cervicitis and those without. Values of $p<0.05$ were considered significant.

\section{Results}

PATIENT CHARACTERISTICS

The clinical and sociodemographic features of the subjects are shown in table 1. All participants were HIV antibody negative on standard ELISA testing. Microscopic evidence of cervicitis as previously defined was found in 12 subjects and absent in nine participants. In general, the two groups of women were comparable with regard to age, presenting symptoms, marital status, and history of previous exposure to sexually transmitted infection. However, use of the oral contraceptive pill was more common among women with cervicitis than those without. Four women with subsequently proved microbiological diagnoses of $C$ trachomatis, $N$ gonorrhoeae, and HSV were excluded from analysis.

CERVICAL CELL SUBSETS

The results of immunofluorescent staining of cervical intraepithelial cells and matched PBMC using purified monoclonal antibodies are summarised in figure 1 . Overall the mean number of cervical CD3+ $\mathrm{T}$ lymphocytes per 10000 events in women with cervicitis was no different from those without cervicitis (118 (SD 26); 130 (47) respectively, $\mathrm{p}=0.81$ ). Mean CD4+ counts were similar in both groups of women (cervicitis 72 (28), without cervicitis 61 (14), $\mathrm{p}=0.72$ ) and the same was true for CD8+ T lymphocytes (cervicitis 52 (19), without cerphocytes were almost absent in all women (cervicitis five (two), without cervicitis two (one), $\mathrm{p}=0.28$ ).

HLA-DR+ cells made up the highest proportion of the leucocytes acquired from cervical samples, and their presence in large were from women with cervicitis (392 (65)) or without (417 (65)), $\mathrm{p}=0.79$. Thus, the dispersion of HLA-DR+ cells in cervical epithelium did not appear to vary with inflammation. However, women with cervicitis were shown to have higher macrophage counts (228 (26)) compared with those without cervicitis (128 (31)), p <0.05.

PERIPHERAL BLOOD CELL SUBSETS

The mean counts of CD3+ T lymphocytes, B lymphocytes, and MHC class II+ cells in peripheral blood per 10000 events were clearly vicitis 48 (11) $\mathrm{p}=0.86)$. Of interest, B lymnumbers was independent of whether samples 
higher than those in cervical epithelium in both groups of women. T lymphocytes made up the greatest proportion of cells acquired from peripheral blood. Upon CD3+ T lymphocyte subset analysis, women with cervicitis had markedly elevated mean CD8+ $\mathrm{T}$ lymphocyte counts compared with those without (cervicitis 1894 (199); without cervicitis 989 (160) respectively, $\mathrm{p}=0.005)$. In contrast, mean CD4+ $\mathrm{T}$ lymphocyte counts in women with cervicitis were no different from those of without cervicitis (3207 (235), 2676 (422) respectively, $\mathrm{p}=0.29$ ). There was no difference in the mean B lymphocyte counts between the two groups (cervicitis 466 (79), without cervicitis 783 (214), $\mathrm{p}=0.19)$. Similarly, statistical analysis showed no difference between mean HLA-DR+, and CD14+ cellular yields in both groups of women (HLA-DR+ cervicitis 1841 (152), without cervicitis 2191 (466), $\mathrm{p}=0.49$; CD14+ cervicitis 987 (158), without cervicitis 1214 (244) $\mathrm{p}=0.44)$.

COMPARISON BETWEEN CERVICAL EPITHELIAL AND PERIPHERAL BLOOD CELL COUNTS

The frequency of $\mathrm{T}$ lymphocytes in peripheral blood was approximately 40-50-fold higher than that in cervical epithelium. Fewer numbers of $\mathrm{B}$ lymphocytes were observed in peripheral blood and these cells were almost absent in cervical epithelium of either group of women. Monocyte/macrophage numbers were approximately $5-10$-fold greater in peripheral blood compared with cervical epithelium. In addition, expression of the MHC class II
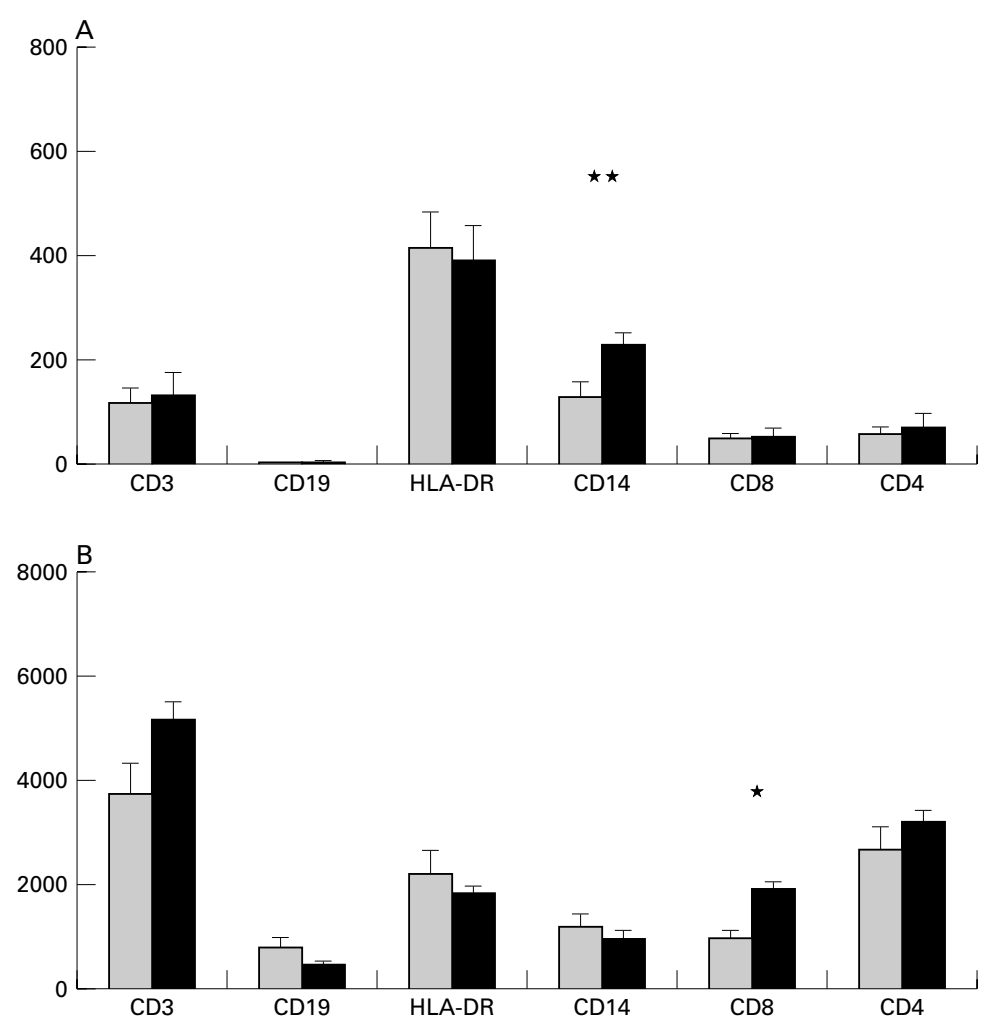

Figure 1 Differences in the recovery of $(A)$ cervical and $(B)$ peripheral blood $C D 45+$ cell subpopulations are shown. The cellular phenotype is on the $x$ axis and the mean number of positive cells per 10000 events on the y axis. Standard error bars are shown on the histogram. Solid bars represent women with cervicitis, women without cervicitis are represented by shaded bars $\left({ }^{\star *} p<0.005 ;{ }^{*} p<0.05\right)$. determinants (HLA-DR+) in cervical epithelium was decreased fivefold compared with peripheral blood.

Thus, within the two compartments there were differences in the predominant cell types found between women with cervicitis and those without cervicitis. Whereas cervical macrophage numbers showed higher proportions in women with cervicitis compared with those without, the same was not true for peripheral blood. In addition, the relative CD8+ $\mathrm{T}$ cell lymphocytosis in peripheral blood of women with cervicitis was not seen in corresponding cervical samples.

\section{Discussion}

Our findings suggest individuals with cervicitis have increased numbers of cervical intraepithelial macrophages compared with those with non-inflamed cervix. Polymorphonuclear leucocytes are commonly found in cervical mucus in the absence of infection or inflammation. Surprisingly, studies of cervical exudate have not demonstrated a corresponding increase in macrophages in such samples. Thus, the local influx of macrophages in inflamed cervical epithelium may represent part of the mucosal immune response to an unidentified microbial pathogen or the body's attempt to repair injured epithelium. ${ }^{16}{ }^{17}$

In this study, the total numbers of cervical epithelial $\mathrm{T}$ lymphocytes did not increase in women with cervicitis. This observation is unexpected and contradicts that of Levine et al who found significantly increased numbers of endocervical CD4+ cells in women with cervicitis. ${ }^{18}$ Of note, many subjects in the latter study had florid chlamydial or gonococcal cervicitis whereas most individuals in our study showed milder degrees of inflammation and were without identifiable pathogens. However, we are unable to discount the possibility that factors such as local pH changes, ${ }^{19}$ timing of last sexual intercourse, ${ }^{20}$ and use of mechanical barrier contraception may have influenced cervical lymphocyte numbers in either group of women.

The paucity of B lymphocytes in cervical epithelial samples of women with cervicitis is more difficult to explain. These cells were similarly almost absent in cervical samples from normal healthy women. ${ }^{11}$ Loss of the CD19 marker during terminal differentiation of B lymphocytes into plasma cells in cervical epithelium is a plausible, though less likely, explanation since both types of cells tend to be particularly prominent in the lamina propria of the human endocervix at histology and are considered responsible for the $\operatorname{IgA}$ and $\operatorname{IgG}$ concentrations in cervical secretions. ${ }^{21}{ }^{22}$

In contrast with findings in cervical epithelia, elevated levels of CD8+ T lymphocyte counts were found in peripheral blood of women with cervicitis. This is of interest since CD8+ T lymphocytes are a critical component of host resistance to intracellular pathogens, in particular, viral infections. ${ }^{23}{ }^{24}$ Further CD8+ T lymphocyte subset characterisation using other surface markers including functional analysis are in progress to ascertain the significance of 
this observation. Whether women with a relatively larger pool of circulating $\mathrm{CD} 8+\mathrm{T}$ lymphocytes are better able to contain sexually transmitted infections or more susceptible to such infections remains to be determined.

These above findings should be interpreted in the context of a limited clinic sample of women at risk of sexually transmitted infection and, therefore, cannot be applied to the general population. Variations in the numbers and phenotype of cervical epithelial cells in the female genital tract including expression of MHC class II+ molecules (HLA DR+ positive cells accounted for the highest proportion of cells acquired from cervical samples among both groups of women) have been shown to depend on the stage of the menstrual cycle. ${ }^{122526}$ It can be argued, therefore, that our findings merely reflect hormonal regulation of immune cells in cervical mucosa at the time of sampling - namely, mid-cycle or oral contraceptive pill use rather than response to antigenic challenge. Furthermore, quantitation of polymorphonuclear leucocytes in cervical exudate does not reliably provide a detailed picture of cervical inflammation.

Taken together, however, our data suggest cervical epithelial macrophages constitute a significant part of the immune response in women with cervicitis. Furthermore, cells capable of immune recognition and protection in the cervix may function somewhat independently of systemic immunity. The manner in which local mucosal and systemic immune cells interact to repel or enhance susceptibility to sexually transmitted infection requires further elucidation.

Conflict of interest: None.

We thank Drs J Durandt, J Morgan, and nursing staff, GUM/ HIV department for their clinical assistance and are grateful for the laboratory support provided by Professor S Knight, Antigen Presentation Group at Imperial College.

Contributors: MK initiated and designed the study and was principal investigator. The analytical method was developed by MP and SP. All authors contributed to interpretation of data and drafting of the paper. MP was supported by Imperial College of Science, Medicine and Technology.

1 Ogra LP, Yamariaka T, Losonsky AG. Local immunological defenses in the genital Tract. In: Reproductive immunology. New York: Alan R Liss Inc, 1981:381-94.

2 Morris BHH, Gatter CK, Stein H, et al. Langerhans cells in human cervical epithelium: an immunological study. $\mathrm{Br} \mathcal{F}$ Obstet Gynaecol 1985;92:974-82.

3 Edwards TNJ, Morris BH. Langerhans cells and lymphocyte subsets in the female genital tract. Br $\mathcal{F}$ Obstet Gynaecol 1985;92:974-82.
4 Parr MB, Parr EL. Antigen recognition in the female reproductive tract: I. Uptake of intraluminal protein tracers in the mouse vagina. F Reprod Immunol 1990;17:101.

5 Bomsel M. Transcytosis of infectious human immunodeficiency virus across a tight human epithelial cell line barrier. Nat Med 1997;3:42-7.

6 McKenzie J, King A, Hare J, et al. Immunocytological characterisation of large granular lymphocytes in normal cervix and HPV associated disease. F Pathol 1991;165:75-80.

7 Gallichan WS, Rosenthal KL. Long term immunity and protection against herpes simplex virus type 2 in the murine female genital tract after mucosal but not systemic immunization. F Infect Dis 1998;177:1155-61.

8 Olaitan A, Johnson MA, MacLean A, et al. The distribution of immunocompetent cells in the genital tract of HIVpositive women. AIDS 1996;10:759-64.

9 Cohen RC, Plummer FA, Mugo N, et al. Increased IL-10 in the endocervical secretions of women with non-ulcerative sexually transmitted diseases: a mechanism for enhanced HIV-1 transmission? AIDS 1999;13:327-32.

10 Given AL, White HD, Stern JE, et al. Flow cytometric analysis of leukocytes in the human female genital tract: comparison of fallopian tube, uterus, cervix and vagina. $\mathrm{Am}$ F Reprod Immunol 1997;38:350-9.

11 Prakash M, Patterson S, Kapembwa M. A rapid noninvasive method for the characterisation of intraepithelial mononuclear cells from the human cervix-uteri. Sex Transm Inf 2001; (www.sextransinf.com).

12 Giglio T, Imro M, Filaci G, et al. Immune cell circulating subsets are affected by gonadal function. Life Sci 1994;54: 1305-12.

13 Brunhaum RC, Paavonen J, Stevens CE, et al. Mucopurulent cervicitis - the ignored counterpart in women of urethritis in men. N Engl F Med 1984;311:1-6.

14 Kiviat NB, Paavonen J, Wolner-Hanssen P, et al. Histopathology of endocervical infections caused by $\mathrm{C}$ trachomatis, HSV and N gonorrhoeae. Hum Pathol 1990;21:831-7.

15 Holmes KK. Lower genital tract infections in women: cystitis, urethritis, vulvovaginitis and cervicitis. In: Holmes KK, Mardh P-A, Sparling PF, et al. Sexually transmitted diseases. 2nd ed. New York: McGraw-Hill, 1990:527-45.

16 Werb Z, Gordon S. Secretion of a specific collagenase by stimulated macrophages. $\mathcal{F}$ Exp Med 1975;142:346-60.

17 Nathan CF. Secretory products of macrophages. $\mathcal{F}$ Clin Invest 1987;79:319-26.

18 Levine WC, Pope V, Bhoomkar A, et al. Increase in endocervical CD4 lymphocytes among women with non-ulcerative sexually transmitted diseases. F Infect Dis 1998; 177:167-74

19 Hill AJ, Anderson JD. Human vaginal leucocytes and the effects of vaginal fluid on lymphocyte and macrophage defense functions. Am $\mathcal{F}$ Obstet Gynecol 1992;166:720-6.

20 Schumacher GFB. Immunology of spermatozoa and cervical mucus. Human Reprod 1998;3:289-300

21 Hulka JP, Omran KF. The uterine cervix as a potential local antibody secretor. Am F Obstet Gynecol 1969;104:440-2.

22 Kutteh WH, Hatch KD, Blackwell RE, et al. Secretor immune system of the female reproductive tract: I Immunoglobulin and secretory component containing cells. Obstet Gynecol 1988;71:56-60.

23 Butz EA, Bevan MJ. Massive expansion of antigen specific CD8+ T-cells during an acute virus infection. Immunity 1998;2:167-75.

24 Slifka MK, Rodriguez F, Whitton JL. Rapid on/off cycling of cytokine production by virus specific CD $8+$ T-cells. Nature 1999;401:76-9.

25 Wira CR, Richardson J, Prabhala R. Endocrine regulation of mucosal immunity: effect of sex hormones and cytokines on the afferent and efferent arms of the immune system in the female reproductive tract. In: Handbook of mucosal immunology 1994:705-18.

26 White HD, Crassi KM, Given AL, et al. CD3+ CD8+ CTL activity within the human female reproductive tract: influence of stage of the menstrual cycle and menopause. $\mathcal{f}$ Immunol 1997;158:3017-27. 